\title{
Efecto de la suplementación con niveles crecientes de probióticos sobre la histomorfometría del intestino delgado del cuy (Cavia porcellus)
}

\author{
Effect of supplementation with increasing levels of probiotics on the \\ histomorphometry of the small intestine of guinea pig (Cavia porcellus)
Jhosseline Puente V. ${ }^{1}$, Fernando Carcelén C. ${ }^{1,5}$, Miguel Ara G. ${ }^{1}$, Sandra Bezada Q. ${ }^{1}$, Amparo Huamán C. ${ }^{2}$, Gilberto Santillán ${ }^{3}$, Rosa Perales ${ }^{3}$, Jorge Guevara V. ${ }^{4}$, Ana Asencios M. ${ }^{1}$

\section{Resumen}

\begin{abstract}
El presente estudio evaluó el efecto de la suplementación con niveles crecientes de un probiótico líquido sobre la histomorfometría del intestino delgado en cuyes. Se utilizaron 50 cuyes machos a partir de los tres días de edad, distribuidos en un diseño completamente al azar de cinco tratamientos con diez repeticiones cada uno: 0, 1, 2 o $3 \mathrm{ml}$ de probiótico o un antibiótico promotor del crecimiento (APC, Zn-Bacitracina). Se tomaron muestras de duodeno, yeyuno e íleon de cada animal a los 84 días de edad y se midió la longitud y ancho de las vellosidades intestinales, la profundidad de las criptas de Lieberkühn y la relación longitud/profundidad. No se evidenciaron patrones consistentes de respuesta para la mayoría de las mediciones en los tres segmentos, excepto una respuesta lineal $(\mathrm{p}=0.047)$ de la relación longitud/profundidad en el duodeno y un efecto positivo $(\mathrm{p}=0.008)$ del APC sobre la longitud de vellosidades en el íleon. Se concluye que, bajo las condiciones del estudio, los niveles del probiótico no provocaron un incremento en las dimensiones de las vellosidades y que, si lo hicieron, el efecto quedó enmascarado por una acelerada tasa de extrusión celular en las vellosidades.
\end{abstract}

Palabras clave: cuy; probiótico; histomorfometría intestinal

${ }^{1}$ Laboratorio de Bioquímica, Nutrición y Alimentación Animal, Facultad de Medicina Veterinaria, Universidad Nacional Mayor de San Marcos, Lima, Perú

${ }^{2}$ Estación Experimental El Mantaro, Centro de Investigaciones IVITA, Universidad Nacional Mayor de San Marcos, Junín, Perú

${ }^{3}$ Laboratorio de Histología, Embriología y Patología Animal, Facultad de Medicina Veterinaria, Universidad Nacional Mayor de San Marcos, Lima, Perú

${ }^{4}$ Escuela Académico Profesional de Ingeniería Agroindustrial, Facultad de Química e Ingeniería Química, Universidad Nacional Mayor de San Marcos, Lima, Perú

${ }^{5}$ E-mail:fcarcelenc@unmsm.edu.pe 
The present study evaluated the effect of supplementation with increasing levels of a liquid probiotic on the histomorphometry of the small intestine in guinea pigs. Fifty male guinea pigs were used from 3 days of age, distributed in a completely randomized design of five treatments with 10 repetitions each: $0,1,2$ or $3 \mathrm{ml}$ of probiotic or an antibiotic growth promoter (AGP, Zn-Bacitracin). Samples of duodenum, jejunum and ileum were taken from each animal at 84 days of age and the length and width of the intestinal villi, the depth of the Lieberkühn crypts and the length/depth relationship were measured. There were no consistent response patterns for most of the measurements in the three segments, except for a linear response $(\mathrm{p}=0.047)$ of the length/depth ratio in the duodenum and a positive effect $(\mathrm{p}=0.008)$ of the AGP over the length of villi in the ileum. It is concluded that, under the conditions of the study, the levels of the probiotic did not cause an increase in the villus dimensions and if they did, the effect was masked by an accelerated rate of cell extrusion in the villi.

Key words: guinea pig; probiotic; gut histomorphometry

\section{INTRODUCCIÓN}

La crianza de cuy ha tenido un incremento considerable en las últimas décadas debido a la alta demanda de su carne en el mercado nacional e internacional. La carne de cuy se caracteriza por tener un alto nivel de proteína y minerales, un bajo nivel de grasa y un exquisito sabor (Ministerio de Agricultura y Riego, 2008). El incremento en la crianza ha traído consigo la necesidad de mejorar la eficiencia productiva en grandes lotes de animales mediante la aplicación de estrategias que regulen la disponibilidad y utilización de nutrientes en el tracto gastrointestinal.

Una de estas estrategias es el uso de antibióticos como promotores de crecimiento (APC). Los APC modifican de manera cualitativa y cuantitativa la microbiota intestinal del hospedero, reducen la cantidad de microorganismos patógenos causantes de enfermedades subclínicas y disminuyen la microbiota normal que compite por nutrientes, logrando con ello, una mejora en la productividad y reducción de la mortalidad de los animales (Dibner y Richards, 2005). Sin embar- go, el uso indiscriminado de los APC ha sido relacionado con la presencia de residuos en los alimentos y con la generación de microorganismos resistentes, los cuales repercuten en la salud pública (Torres y Zarazaga, 2002).

En la búsqueda de opciones que maximicen la producción animal y, al mismo tiempo, garanticen la inocuidad sanitaria del producto para los consumidores, surgen los probióticos, los cuales han sido definidos como microrganismos vivos, los cuales administrados en cantidades adecuadas en la dieta ejercen un efecto beneficioso sobre la salud del hospedador, mediante una mejora de la fisiología del individuo (FAO/OMS, 2001). La administración de probióticos ya sea en forma uni o multi-específica ha demostrado cierto grado de efectividad en las propiedades de la microbiota nativa intestinal (Higgins et al., 2007.) Ellos proporcionan condiciones favorables para el desarrollo de microorganismos benéficos del tracto gastrointestinal y también funcionan como agentes tróficos, estimulando y acelerando el proceso de mitosis que ocurre en la región de la cripta-vellosidad intestinal, incrementando el número de células y, por consiguiente, la 
integridad de la barrera intestinal, al mismo tiempo que se produce una mejor absorción de nutrientes.

Los probióticos surgen como una alternativa al uso de APC, con la premisa de mantener la inocuidad de la carne, además de generar efectos en el desarrollo del tracto gastrointestinal favoreciendo la prevención de infecciones intestinales. Los escasos resultados publicados sobre el uso de probióticos en la alimentación del cuy y su efecto sobre la histomorfometría intestinal justifican la realización del presente estudio, cuyo objetivo fue determinar el efecto de la suplementación de la dieta de cuyes de engorde con niveles crecientes de un probiótico líquido sobre el desarrollo de vellosidades intestinales y las criptas de Lieberkühn.

\section{Materiales y Métodos}

\section{Lugar del Estudio}

El estudio se realizó entre febrero y abril de 2015, con una duración de 10 semanas, en la Unidad de Cuyes de la Estación Experimental El Mantaro del Centro de Investigación IVITA, ubicada en el km 34 de la carretera Huancayo-Jauja, distrito de El Mantaro, departamento de Junín, Perú. La Estación está a una altitud de $3320 \mathrm{msnm}$. La evaluación histológica se realizó en el Laboratorio de Histología, Embriología y Patología Animal de la Facultad de Medicina Veterinaria de la Universidad Nacional Mayor de San Marcos, en Lima.

\section{Arreglo Experimental}

Se usaron 50 cuyes hembras, preñadas, provenientes de la línea materna ProlíficaLechera, la cual es utilizada como progenitor materno en la generación de los Cuyes Reproductores Geniales en la Estación IVITA-El Mantaro (Jiménez y Huamán, 2010). Una semana antes de la fecha probable de parto, las hembras fueron aleato- riamente distribuidas en cinco tratamientos a razón de 10 hembras por tratamiento. Las madres fueron alojadas en pozas individuales equipadas con comederos y bebederos y alimentadas a discreción con una mezcla forrajera a partes iguales de ryegrass italiano (Lollium multiflorum) cv Tama y trébol rojo (Trifolium pratense) cv Queniqueli, complementada con afrechillo de trigo. El agua de bebida se suministró a voluntad en bebederos de arcilla, reemplazándose el sobrante cada día.

Las madres recibieron la suplementación correspondiente a cada tratamiento desde el tercer al séptimo día del parto. Las crías fueron destetadas a los 14 días de nacidas seleccionándose al azar una cría macho por cada madre para formar grupos de 10 crías por tratamiento. Las crías fueron trasladados a pozas individuales de $0.7 \times 0.8 \times 0.5 \mathrm{~m}$ previamente limpiadas, flameadas, desinfectadas con amonio cuaternario y luego con cal y acondicionadas con una cama nueva de paja. El acondicionamiento y la dieta base, incluyendo el racionamiento, fueron iguales a los empleados con las madres. La aplicación de los tratamientos fue repetida en los periodos 16-20 y 46-50 días de edad. La secuencia de aplicación pretendió sembrar bacterias benéficas en el intestino del neonato (días 3 a 7), desplazar bacterias patógenas oportunistas durante el estrés del destete (días 16 a 20) y propiciar una mejor salud intestinal al inicio del desarrollo y engorde (días 46 a 50) (Castillo, 2006).

\section{Probiótico y APC}

Los tratamientos consistieron en la suplementación de $0,1,2 \mathrm{o} 3 \mathrm{ml}$ del probiótico o con un APC. El probiótico usado en este estudio se elaboró a partir de seis especies bacterianas aisladas de la mucosa del yeyuno e íleon y de heces de cuyes de 2, 3, 4, 5 y 6 días de edad. Las bacterias fueron cultivadas en medios enriquecidos y medios diferenciales y, previa caracterización fenotípica, identificadas por técnicas de biología molecular (Castillo, 2006). Las especies 
bacterianas y sus respectivas concentraciones fueron: Enterococcushirae $2.1 \times 10^{10}$ bacterias $/ \mathrm{ml}$, Lactobacillus reuteri $3.3 \times 10^{10}$ bacterias $/ \mathrm{ml}$, Lactobacillus frumenti $3.1 \times 10^{10}$ bacterias $/ \mathrm{ml}$, Lactobacillus jhonsoni $2.2 \times 10^{10}$ bacterias $/ \mathrm{ml}$, Strepcoccus thoraltensis $2.3 \times 10^{10}$ bacterias $/ \mathrm{ml}$ y Bacillus pumillus $3.3 \times 10^{10}$ bacterias $/ \mathrm{ml}$. Se utilizó 50 $\mathrm{ml}$ de cada una de estas suspensiones que fueron diluidas con $600 \mathrm{ml}$ de ácido láctico $25 \%$ y $100 \mathrm{ml}$ de agua deionizada estéril.

En los tratamientos de 1, 2 o $3 \mathrm{ml}$, la suspensión probiótica diluida fue administrada diariamente por vía oral, usando una jeringa de $1 \mathrm{ml}$. En los tratamientos de $0 \mathrm{ml} \mathrm{y}$ APC se reemplazó la suspensión probiótica por agua destilada. El APC utilizado en el tratamiento correspondiente fue ZincBacitracina (Promozinb ${ }^{\hat{a}} 10 \%$, Laboratorios CUSA) administrado en mezcla con el afrechillo a una concentración de 300 ppm (3 $\mathrm{kg}$ de Promozimb ${ }^{\hat{a}}$ por $1000 \mathrm{~kg}$ de afrechillo).

\section{Histomorfometría Intestinal}

Los cuyes se sacrificaron a los 84 días de edad mediante desnucado y degüello. Se extrajo el intestino delgado para tomar muestras de tres segmentos: $1 \mathrm{~cm}$ de largo del duodeno (a $3 \mathrm{~cm}$ del píloro), yeyuno (sección media de la medición total de las asas yeyunales) e íleon (a $3 \mathrm{~cm}$ de la unión ileocecal). Las muestras se fijaron por más de $24 \mathrm{~h}$ en formol bufferado $10 \%$ y luego se redujeron a porciones de 4 a $5 \mathrm{~mm}$ de largo para ser lavadas y deshidratadas con alcohol etílico $70 \%$. Posteriormente, las muestras fueron aclaradas en xilol e incluidas en parafina para obtener cortes transversales de la mucosa intestinal de 5 ìm de espesor y ser teñidas con hematoxilina-eosina.

Para la medición del largo y ancho de las vellosidades intestinales y la profundidad de las criptas de Lieberkühn se siguió un protocolo adaptado de Gava (2012) y Bravo (2012): En cada corte histológico se selec- cionaron 8 a 10 campos a un aumento de 10x, midiendo la totalidad de vellosidades (longitud y ancho) y las profundidades de las criptas. La longitud de la vellosidad se midió desde el ápice de la vellosidad hasta el ápice de la entrada a la cripta. El ancho de la vellosidad se midió en el punto medio vertical de la vellosidad elegida. La profundidad de la cripta se midió desde la entrada a la cripta hasta la zona basal de la misma (Figura 1). Las mediciones se realizaron con ayuda del programa de adquisición de imágenes Leica LAS EZ ${ }^{\hat{a}}$ (Leica Microsystems ${ }^{\hat{a}}$ ) instalado en un computador conectado a un microscopio Leica ${ }^{\circledR}$ DM500, que incluía una cámara Leica ${ }^{\circledR}$ ICC50.

Se obtuvieron promedios de largo y ancho de vellosidades y profundidad de cripta de cada segmento intestinal. La relación longitud de la vellosidad/profundidad de la cripta resultó de la división del promedio de la longitud de la vellosidad y el promedio de la profundidad de la cripta de Lieberkühn.

\section{Análisis Estadístico}

Los datos obtenidos fueron sometidos a un análisis de varianza correspondiente a un diseño completamente al azar con 5 tratamientos y 10 repeticiones para las variables de respuesta longitud y ancho de vellosidades, profundidad de cripta y relación longitud/profundidad. Las respuestas morfométricas lineales y cuadráticas a los niveles crecientes del probiótico o a la inclusión del APC fueron evaluados mediante contrastes (Steel et al., 1997) dentro de segmentos intestinales. Posterior a la evaluación preliminar de la interacción tratamientos x segmentos, las diferencias entre segmentos en promedio de tratamientos fueron examinadas mediante un análisis de varianza de mediciones repetidas y una prueba múltiple de comparación de medias de Tukey (Bretz et al., 2011). El nivel de significancia usado en todas las pruebas estadísticas fue 0.05. Los cálculos estadísticos fueron realizados con ayuda del programa R 3.4.3 (R Core Team, 2013). 


\section{Resultados y Discusión}

Las respuestas lineales y cuadráticas a los niveles crecientes del probiótico y el efecto del APC en términos de la longitud y ancho de las vellosidades intestinales y de la profundidad de la cripta de Lieberkün para cada segmento intestinal se presentan en el Cuadro 1 . No se evidenciaron interacciones entre tratamientos x segmentos intestinales. En general, las diferencias en la morfometría intestinal entre los segmentos del intestino delgado fueron estadísticamente significativas $(\mathrm{p}<0.001)$, a excepción del ancho de vellosidad. Tanto para longitud y profundidad de vellosidad como para profundidad de cripta los valores se dieron en el orden duodeno $>$ yeyuno $>$ íleon.
No se obtuvieron patrones lineales ni cuadráticos para longitud, ancho ni profundidad en el segmento duodenal con respecto a los niveles crecientes del probiótico. Solo la relación longitud/profundidad mostró una respuesta linealmente significativa $(\mathrm{p}=0.047)$. En el segmento yeyuno tampoco se observó respuesta a los incrementos del probiótico ni a la inclusión del APC. En el íleon, por su lado, la aplicación del APC incrementó de manera significativa $(\mathrm{p}=0.008)$ la longitud de la vellosidad intestinal. Ningún otro tratamiento tuvo efectos significativos sobre la morfometría en este segmento.

Aun cuando varios de los mecanismos del efecto benéfico de los probióticos permanecen sin dilucidar, la supresión del conteo viable de bacterias perjudiciales a través de

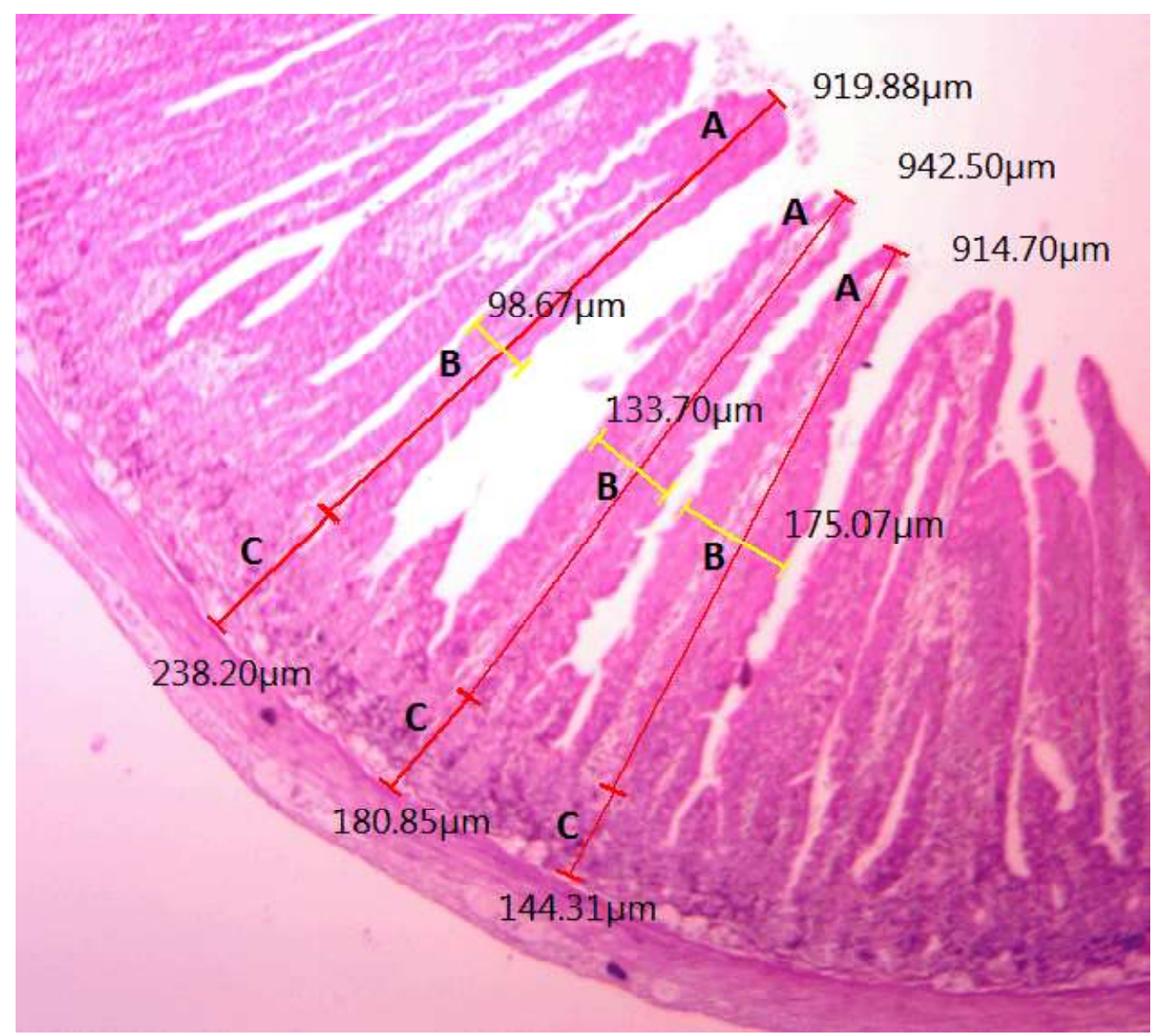

Figura 1. Corte histológico de duodeno de cuy. Se muestra los puntos de referencia para la medición del largo (A) y ancho (B) de vellosidad intestinal y la profundidad (C) de las criptas de Lieberkühn. HE, 10x 
Cuadro 1. Respuestas lineal y cuadrática a los niveles crecientes de probiótico y efecto del antibiótico promotor del crecimiento (APC) en términos de longitud y ancho de vellosidades intestinales de cuy, profundidad de la cripta de Lieberkühn y relación longitud/profundidad $(\mathrm{L} / \mathrm{P})$ de las vellosidades para tres secciones del intestino de cuy

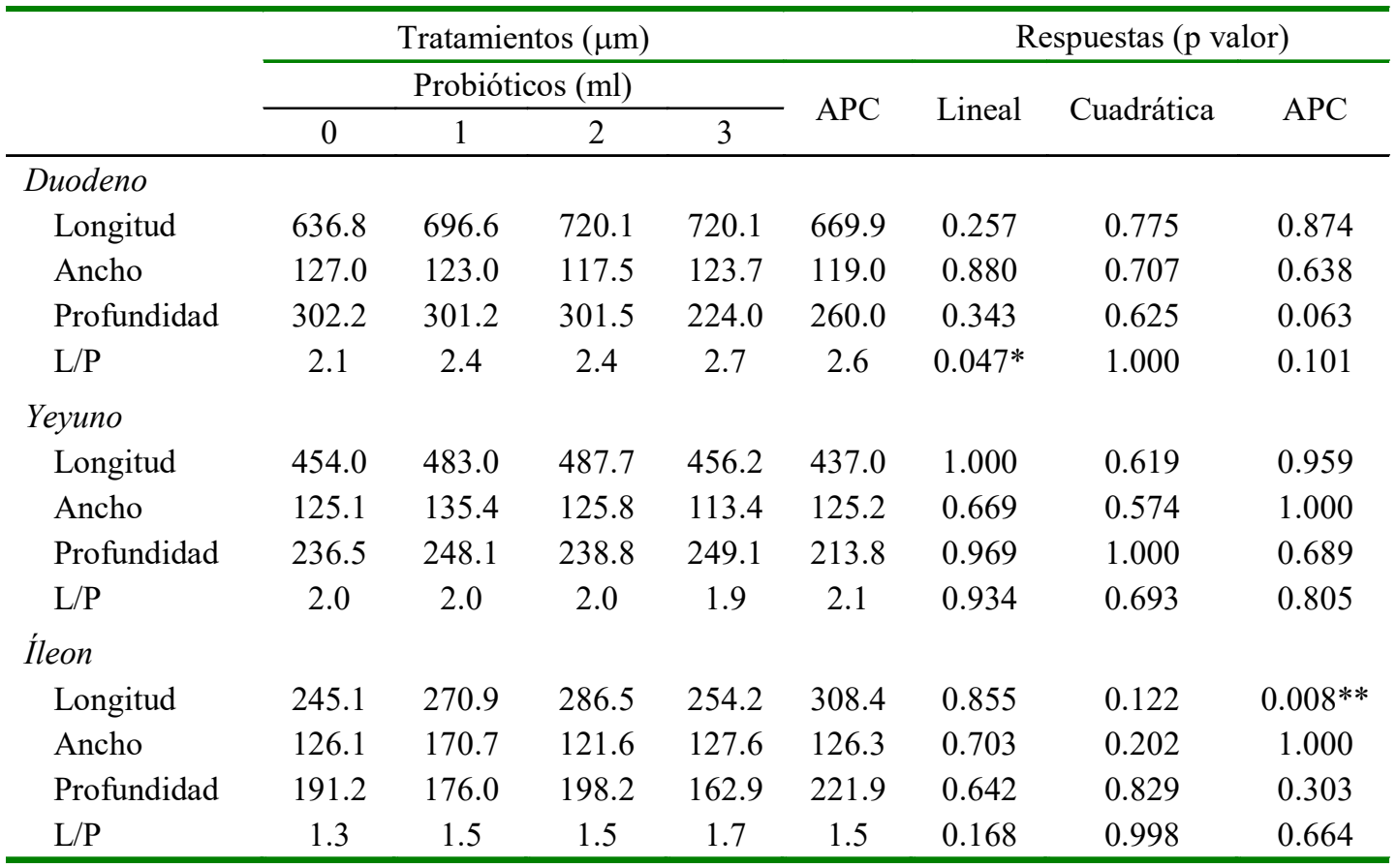

Promedios de 10 repeticiones

* Respuesta significativa a $0.05 ;{ }^{* *}$ Respuesta significativa a 0.01

la producción de compuestos antibióticos o por la competencia por nutrientes o por sitios de adhesión, la modificación del metabolismo de las bacterias perjudiciales, y el estímulo de la inmunidad por incremento de los niveles de antibióticos o de la actividad de los macrófagos parecen ser los más citados (Fuller, 1989; Soccol et al., 2010). Otro mecanismo, más relacionado con la mejora del comportamiento productivo en animales suplementados con probióticos tiene que ver con un efecto trófico. Ichikawa et al. (1999) demostraron un incremento en la tasa de proliferación celular en las criptas del intestino delgado y grueso de ratas suplementadas con probióticos a base de Lactobacillus casei y Clostridium butyricum de $25-50 \%$ en el yeyuno e íleon, $70 \%$ en el ciego y más de $200 \%$ en el colon distal. El efecto es atribuible a un incremento en la tasa neta de pro- ducción de ácidos grasos de cadena corta (AGCC) por parte del probiótico (Sakata et al., 1999). Los AGCC son metabolitos de la fermentación bacterial, los cuales, bajo ciertas condiciones estimulan la producción de células epiteliales intestinales (Sakata, 1987). El efecto global, previsto un adecuado balance entre renovación y pérdida celular, es un incremento en la capacidad de absorción del intestino y la preservación de la barrera intestinal.

Varios resultados experimentales parecen confirmar este mecanismo. En pollos de engorde, Pelicano et al. (2003), tras la adición de cultivos de Bacillus subtilis, Bacillus licheniformis, Lactobacillus reuteri, Lactobacillus johnsonii y Saccharomyces cerevisiae a la ración, observaron un incremento de $39.7 \%$ en la longitud de las 
vellosidades intestinales en el duodeno, no observándose este efecto en el yeyuno e íleon. Similarmente, Ramos et al. (2011) encontraron incrementos significativos en la longitud de las vellosidades del duodeno con el uso de probióticos en la dieta, pero no así en el yeyuno ni en el íleon ni en la profundidad de las criptas. Por otro lado, Song et al. (2014) evidenciaron que Bacillus licheniformis, Bacillus subtilis y Lactobacillus plantarum suplementados como probióticos aumentaron significativamente la longitud de las vellosidades del duodeno, pero no presentaron ningún efecto sobre la profundidad de cripta, ni sobre la relación longitud de la vellosidad/profundidad de la cripta.

Serrano (2015) y Samanya y Yamauchi (2002) en ensayos con probióticos en pollos encontraron que las dosis más bajas fueron suficientes para incrementar la longitud de las vellosidades del duodeno resultando ineficaces las dosis más altas. Por otro lado, Sen et al. (2012) observaron vellosidades más largas al suplementar con 0.30 y $0.45 \%$ de probiótico en el alimento, siendo ineficaces dosis inferiores. Aparentemente, el efecto relacionado a una dosis en particular podría deberse a diversos factores, como la edad del animal, los microorganismos y cepas que conforman el probiótico y la viabilidad y capacidad de persistir en el hospedero (Serrano, 2015).

Las experiencias en cuyes con probióticos son relativamente escasas; sin embargo, se pueden mencionar los estudios de Bravo (2012) y de Vallejos et al. (2015) con AGCC para evaluar la morfometría intestinal, donde encontraron que los ácidos orgánicos tuvieron efectos positivos, principalmente sobre la relación longitud/profundidad, traducidos en vellosidades más largas y criptas menos profundas, siendo las respuestas más marcadas para las dosis de 200 y 300 ppm de la mezcla de ácidos orgánicos y 300 ppm de butirato de sodio.
En el presente estudio no se obtuvo un patrón de respuesta lineal o cuadrática en morfometría intestinal a dosis crecientes de un consorcio probiótico en ninguno de los segmentos intestinales, a excepción de una respuesta lineal significativa para la relación longitud/profundidad en el duodeno. Resultados similares han sido obtenidos por Rodríguez et al. (2010), luego de suministrar probióticos a partir del día 21 de crecimiento a pollos de engorde. En porcinos, ni Walsh et al. (2007), quienes suplementaron animales de 21 días de edad con Lactobacillus acidophilus y Enterococcus faecium, vía oral a una única dosis de $5 \mathrm{ml}$ con $10^{9} \mathrm{UFC} / 1$, ni Marinho et al. (2007), quienes suplementaron cerdos de 35 días de edad con Saccharomyces cerevisiae en el alimento a una dosis de $6 \times 10^{8} \mathrm{UFC} / \mathrm{kg}$ por 21 días pudieron evidenciar cambios en la longitud de vellosidades ni en la profundidad de las criptas.

La respuesta morfométrica intestinal a un tratamiento puede ser considerada como un balance entre la renovación celular (proliferación y diferenciación) en las criptas y la pérdida celular por extrusión en el ápice de las vellosidades. La longitud y el ancho de las vellosidades despenden del número de células que las componen; consecuentemente, vellosidades más largas o anchas o relaciones longitud/profundidad altas reflejan un balance favorable a la renovación celular, ya sea por una ausente o baja extrusión y una alta tasa de renovación. Vellosidades más cortas reflejan un balance favorable a la extrusión, ya sea por una pérdida normal de células o como producto de la inflamación producida por los patógenos o sus toxinas. En estas condiciones, una baja relación longitud/profundidad indicaría una alta tasa de renovación celular, pero insuficiente para incrementar el tamaño de las vellosidades (Uni et al., 1998; Awad et al., 2009; Clevers, 2013). Estos mecanismos sugieren que el rol del probiótico podría ser doble, pues previene la extrusión por inflamación ocasionada por 
bacterias patógenas al impedir, por los mecanismos ya señalados (Fuller, 1989; Soccol et al., 2010) la colonización en el intestino y, al mismo tiempo, estimula la proliferación celular en el epitelio por la producción de AGCC (Ichikawa et al. 1999; Sakata et al., 1999).

La falta de un patrón consistente de respuesta en morfometría a la suplementación con niveles crecientes del probiótico en el presente estudio indicaría que los mecanismos mencionados no han actuado bajo las condiciones experimentales, o que cualquier efecto en el tamaño de vellosidades ha quedado equilibrado con una tasa equivalente de extrusión, ya sea bajo condiciones normales o como producto de la inflamación por bacterias patógenas. No obstante, esto último es poco probable dado el bajo desafío de campo en las condiciones del experimento y la ausencia de una respuesta significativa a la adición del APC. Excepciones a estos resultados son la respuesta lineal $(p=0.047)$ en la relación longitud/profundidad al probiótico en el duodeno y el incremento $(\mathrm{p}=0.008)$ de la longitud de la vellosidad en el íleon en respuesta al APC.

La respuesta lineal en el duodeno es un compuesto de incrementos marginales en la longitud de la vellosidad y de una reducción de la profundidad cripta en las dosis más altas del probiótico. Por otro lado, la respuesta en longitud de vellosidades al APC en el íleon sería atribuible a una reducción de la extrusión acelerada en las vellosidades debido a la acción bactericida o bacteriostática del APC (Dibner y Richards, 2005). No es claro, sin embargo, por qué esta respuesta no se produjo en el duodeno o en el yeyuno.

Diferentes ejemplos de la literatura mencionan el efecto positivo de los probióticos en la alimentación y productividad animal, a través de la mejora de la absorción y la preservación de la integridad de la barrera intestinal. Sin embargo, los resultados de las investigaciones con probióticos son aún contradictorias. La variación en los resultados puede deberse a múltiples factores como la edad de los animales, el proceso de fabricación del producto, el tipo de microorganismo que se utiliza, la viabilidad del probiótico después de la preparación, los factores de manejo o ambientales, la vía de administración, las condiciones higiénicas del galpón y la utilización de antibióticos en combinación con prebióticos (Torres-Rodríguez et al., 2007; Vicente et al., 2007.)

\section{Conclusiones}

Aun cuando los modelos e hipótesis sobre el efecto de los probióticos sobre la morfometría intestinal parecen bien fundamentados, no se ha podido evidenciar, en términos generales, una respuesta consistente en longitud y ancho de vellosidades intestinales, profundidad de criptas y relación longitud/profundidad a niveles crecientes del probiótico en el duodeno, yeyuno o íleon de cuyes a los 84 días de edad. Solo se tuvo la excepción de una respuesta lineal en la relación longitud/profundidad en el duodeno y una respuesta en longitud de vellosidad al APC (Zn-Bacitracina) en el íleon.

\section{Literatura Citada}

1. Awad WA, Ghareeb K, Abdel-Raheem S, Böhm J. 2009. Effects of dietary inclusion of probiotic and synbiotic on growth performance, organ weights, and intestinal histomorphology of broiler chickens. Poultry Sci 88: 49-55. doi: 10.3382/ps.2008-00244

2. Bravo A. 2012. Efecto de la suplementación de ácidos orgánicos sobre la morfometría intestinal en cuyes (Cavia porcellus) de crecimiento y engorde. Tesis de Médico Veterinario. Lima: Univ. Nacional Mayor de San Marcos.76 p.

3. Bretz, F, Hothorn T, Westfall P. 2011. Multiple comparisons using R. Boca Raton, FL, USA: CRC Press. 182 p. 
4. Castillo MSG 2006. Development of gut microbiota in the pig: modulation of bacterial communities by different feeding strategies. Tesis Doctoral. Barcelona, España: Univ. Autónoma de Barcelona. $233 \mathrm{p}$.

5. Clevers H. 2013. The intestinal crypt, a prototype stem cell compartment. Cell 154: 274-284. doi: 10.1016/j.cell.2013.07.004

6. Dibner JJ, Richards JD. 2005. Antibiotic growth promoters in agriculture: history and mode of action. Poultry Sci 84: 634-643. doi: 10.1093/ps/84.4.634

7. FAO/OMS. 2001. Evaluation of health and nutritional properties of probiotics in food including powder milk with live lactic acid bacteria. [Internet]. Disponible en: http://www.fao.org/tempref/docrep/fao/ meeting/009/y6398e.pdf

8. Fuller R. 1989. Probiotics in man and animals. J Appl Bacteriol 66: 365-378. doi: 10.1111/j.1365-2672.1989.tb05105.x

9. Gava S. 2012. Metodologia de morfometria intestinal em frangos de corte. Tesis de Maestría. Brasil: Universidade Federal do Rio Grande Do Sul. 51 p.

10. Higgins SE, Erf GF, Higgins JP, Henderson $S N$, Wolfenden $A D$, Gaona-Ramirez, G, Hargis BM. 2007. Effect of probiotic treatment in broiler chicks on intestinal macrophage numbers and phagocytosis of by abdominal exudate cells. Poultry Sci 86: 2315-2321. doi: 10.3382/ps.2007-00123

11. Ichikawa H, Kuroiwa T, Inagaki A, Shineha R, Nishihira T, Satomi S, Sakata T. 1999. Probiotic bacteria stimulate gut epithelial cell proliferation in rat. Digest Dis Sci 44: 2119-2123.

12. Jiménez, R, Huamán A. 2010. Cuyes genéticamente geniales: manual para el manejo de reproductores híbridos especializados en producción de carne. Lima, Perú: Univ. Nacional Mayor de San Marcos. $175 \mathrm{p}$.

13. Marinho MC, Pinho MA, Mascarenhas RD, Silva FC, Lordelo MM, Cunha LF, Freire JPB. 2007. Effect of prebiotic or probiotic supplementation and ileo rectal anastomosis on intestinal morphology of weaned piglets. Livest Sci 108: 240-243. doi: 10.1016/j.livsci.2007.01.084

14. Ministerio de Agricultura y Riego. 2008. Cuyes. [Internet]. Disponible en: $\mathrm{http} / / /$ www.minagri.gob.pe/portal/40sector-agrario/situacion-de-las-actividades-de-crianza-y-producci/300-cuyes

15. Pelicano ER, de Souza P, de Souza $H B, O b a$ A, Norkus E, Kodawara $L$, de Lima TM. 2003. Morfometria e ultra-estrutura da mucosa intestinal de frangos de corte alimentados com dietas contendo diferentes probióticos. Rev Port Ciênc Vet 98: 125-134.

16. $R$ Core Team. 2013. R: a language and environment for statistical computing. $\mathrm{R}$ Foundation for Statistical Computing. Vienna, Austria. URL http://www.Rproject.org/

17. Ramos LS, Lopes J, Silva SM, Silva FE, Ribeiro M. 2011. Desempenho e histomorfometria intestinal de frangos de corte de 1 a 21 dias de idade recebendo melhoradores de crescimento. R Bras Zootec 40: 1738-1744. doi: 10.1590/ S1516-35982011000800017

18. Rodríguez, F, Eliecer J, Alsina S. 2010. Morphological changes in intestinal villi in broiler chickens fed from 21 days with a diet supplemented with $10 \%$ of efficient microorganisms. CITECSA 1: 40-46.

19. Samanya M, Yamauchi KE. 2002. Histological alterations of intestinal villi in chickens fed dried Bacillus subtilis var. natto. Comp Biochem Phys A 133: 95-104. doi: 10.1016/S1095-6433(02)00121-6

20. Sen S, Ingale SL, Kim YW, Kim JS, Kim KH, Lohakare JD, Kim EK, et al. 2012. Effect of supplementation of Bacillus subtilis LS 1-2 to broiler diets on growth performance, nutrient retention, caecal microbiology and small intestinal morphology. Res Vet Sci 93: 264-268. doi: 10.1016/j.rvsc.2011.05.021

21. Serrano TM. 2015. Evaluación de la inclusión de probióticos en el agua de bebida de pollos broiler sobre parámetros 
productivos y morfometría intestinal. Tesis de Médico Veterinario. Chile: Univ. de Chile. 26 p.

22. Sakata T. 1987. Stimulatory effect of short-chain fatty acids on epithelial cell proliferation in the rat intestine: a possible explanation for trophic effects of fermentable fibre, gut microbes and luminal trophic factors. Brit J Nutr 58: 96-103. doi: 10.1079/BJN19870073

23. Sakata T, Kojima T, Fujieda M, Miyakazawa M, Takahashi M, Ushida K. 1999. Probiotic preparations dosedependently increase net production rates of organic acids and decrease that of ammonia by pig cecal bacteria in batch culture. Digest Dis Sci 44: 1485-1493.

24. Soccol CR, Venderberghe LP, Spier M, Medeiros AB, Yamaghishi C, Lindner J, Pandy A, et al. 2010. The potential of probiotics: a review. Food Technol Biotech 48: 413-434.

25. Song J, Xiao K, Ke L, Jiao LF, Hu CH, Diao QY, Shi B, Zou T. 2014. Effect of a probiotic mixture on intestinal microflora, morphology, and barrier integrity of broilers subjected to heat stress. Poultry Sci 93: 581-588. doi: 10.3382/ps.2013-03455

26. Steel RGD, Torrie JH, Dickey DA. 1997. Principles and procedures of statistics: a biometrical approach. $3^{\circ} \mathrm{ed}$. WCB McGraw-Hill. 666 p.

27. Torres C, Zarazaga M. 2002. Antibióticos como promotores del crecimiento en animales: ¿vamos por el buen camino? Gaceta Sanit 16: 109-112.
28. Torres-Rodríguez A, Donoghue AM, Donoghue DJ, Barton JT, Tellez G, Hargis BM. 2007. Performance and condemnation rate analysis of commercial turkey flocks treated with a Lactobacillus spp-based probiotic. Poultry Sci 86: 444-446.

29. Uni Z, Ganot S, Sjlan, G. 1998. Posthatch development of mucosal function in the broiler small intestine. Poultry Sci 77:75-82. doi: 10.1093/ps/ 86.3.444

30. Vallejos D, Carcelén F, Jiménez R, Perales R, Santillán G, Ara M, Quevedo W, Carzola F. 2015. Efecto de la suplementación con butirato de sodio en la dieta de cuyes (Cavia porcellus) de engorde sobre el desarrollo de las vellosidades intestinales y criptas de Lieberkühn. Rev Inv Vet Perú 26: 395403. doi: 10.15381/rivep.v26i3.11186

31. Vicente J, Higgins S, Bilke L, Tellez G, Donoghue D, Donoghue A, Hargis BM. 2007. Effect of probiotic culture candidates on Salmonella prevalence in commercial turkey houses. J Appl Poultry Res 16: 471-475. doi: 10.1093/ japr/16.3.471

32. Walsh MC, Saddoris KL, Sholly DM, Hinson RB, Sutton AL, Applegate TJ, Richert BT, et al. 2007. The effects of direct fed microbials delivered through the feed and/or in a bolus at weaning on growth performance and gut health. Livest Sci 108: 254-257. doi: 10.1016/ j.livsci.2007.01.051 